MULTIPLE PTERYGIUM SYNDROME IN IDENTICAL TWINS Carlos Duran S., Roger L. Ladda, Keith H. Marks. The

\section{Hershey PA.}

Multiple pterygium syndrome is a relatively rare

disorder characterized by pterygia of the neck, axilla, digits, antecubital, popliteal and intercrural areas. Affected individuals may also have multiple congenital contractures and the diagnosis of arthrogryposis is frequently the presenting complaint. We describe monochorionic diamniotic female twins with multiple pterygium syndrome. The twins were born at 32 weeks' gestation to a 19-year-old G2 P1001. The suspicion of cystic hygroma in one twin was raised during ultrasound screening of the pregnancy at 22 weeks' gestation and the cystic mass was screening of the pregnancy at 22 weeks gestation and the cystic mass was found in Twin B at delivery; it resolved in the first few days of life. Each
newborn presented with flexion deformities of the upper and lower extremities, pterygia of the neck, upper arms, antecubital and poplitea regions. The most prominent pterygia involved the upper extremities and neck. Each had angular facies with micrognathia. Twin A had left sided talipes equino varus with right side vertical talus. Twin B has bilateral talipes equino varus. Twin A had a cleft of the soft palate. Twin B had Tetralogy of Fallot requiring a modified Blalock Taussig shunt in the Tetralogy of Fallot requiring a modified Blalock both. Although most cases are sporadic, some appear to be familial and may follow an autosomal recessive pattern of inheritance. Cardiac anomalies in this condition are infrequently reported. Twin $A$ responded well to treatment and was discharged to the referring hospital. Twin B remains in our hospital and still requires ventilatory assistance. Affecled identical twins have not previously been reported. This diagnosis should always be considered on a newborn with pterygia.

HEMIFACIAL HYPOPLASIA, HYPOPIGMENTATION, AND DIGITAL ANOMALY SYNDROME, DI Eteson, RD Clark $\frac{H \text { Kawamete, and } \frac{Y}{Y} \text { Seteguchi, }}{\text { (Sponsored by LJShapiro) Harbor-UCLA Med }}$

327 (Sponsored by LJ Shapiro) Harbor-UCLA Med Depts Peds \& Plastic Surg, Los Angeles, CA. We report a unique syndrome of craniofacial anomalies, hypopigmentation and digital abnormalities in 2 unrelated children. Patient $1, a 5 y .0$. male of normal intelligence, has right facial hypoplasia, microdontia, hypodontia, and focal areas of scalp alopecia. There is linear hypopigmentation on the lower lip. chest, right arm, hand and leg. The right 2nd metatarsal is short. Growth and development were normal. Patient 2 is a 7 Y.o. female with facial features identical to patient lincluding right facial hypoplasia, eyelid coloboma, focal scalp alopecia an mented skin are present on her left chest, shoulder and right right leg. The right 2nd metatarsal is short and there is postaxial polysyndactyly. This patient also has imperforate anus and a double collecting system. Intelligence is normal.

Chromosome analysis of peripheral blood and normally pigmented and depigmented skin from both patients was normal, ruling out mosaicism. We propose that this new syndrome may involve a defect in neural crest cell proliferation or migration causing both the facial hypoplasia and pigmentary abnormalities.

POSTNATAL PLACIOCEPIIALY: PATHOGENESIS AND THERAPY IN 40 CASES (1981-86), John M. Graham, Jr., Catherine E. Charman, Robert Chaisson, (Spon, by R.z. Kiein).

328 Dartmouth Medical School, Dartmouth-Hitchcock Medical Center, Dept. Maternal \& Child Health, Dept. of Surgery, (Section of Orthopaedics), Hanover NH 03756

We report 40 cases of postnatal plaglocephaly seen over a $6 \mathrm{yr}$ perfod (1981-86). Twenty cases had mild to moderate plagiocephaly (10 males, 10 females) due to muscular torticollis and responded to physical therapy and repositioning within the first few ponths of life. In 3 instances, a head positioning device was helpful; in 2 instances where no consistent therapy was attempted the cranial deformity persisted. An additional 9 cases had severe plagiocephaly due to persistent muscular torticollis (8 males, 1 female). When the above measures falled to correct cranial symmetry by 5 to 6 months, helmet therapy was instituted with excellent results. Another 5 cases ( 3 males, 2 females), had marked occipital flattening from prolonged use of an Infant Seat; 3 improved with repositfoning alone, while 2 with associated muscular torticollis required either head positioning device or helmet. Four children with medical problems resulting in prolonged recumbency (CNS abnormalities, intestinal atresia, TE fistula) and associated mild torcicollis, responded to simple repositioning. Two other children with unremitting torticollis due to Klippel-Fell anomaly required helmet therapy. Neck stretching exercises and repositioning were most effective in correcting plagfocephaly when instituted early in the first year of iffe. When torticollis was severe (more common in males) or due to underlying vertebral anomalles, helmet therapy was effective.
PROSPECTIVE MSAFP SCREENING FOR DOWN SYNDROME: THI BAYLOR EXPERIENCE. Frank Greenberg, Judy Garza,

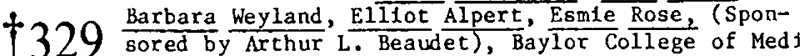
cine, Institute for Molecular Genetics and Departme of Medfcine, Houston, Texas.

Af ter the fintial reports of the association of fetal trisomy 21 with low maternal serum alpha fetoproteln (MSAFP) levels in retrospective studies in 1984, we began using low MSAFP levels as a means of screenting for an increased rlsk of Down syndrome using reagents fxom Clinical Assays. In 1985, a total of 4929 wonen were screened, of whom $312(6.3 \%)$ had an inftclal low MSAFP levels. Of these women, 217 (70\%) had leve1s below the level of rellability of the assay and all but 33 had normal levels on repeat $1-2$ weeks latex. None of these women had a fetus or jnfant with trisomy 21 by amnlocentests or at birth. N.nety-five women $(1.9 \%)$ had levels below half the median. of these women, 12 had persistently low levels on repeat. A total of 21 anntocenteses were done in thts group. Three fetuses with trisomy 21 and one fetus whth trisomy 18 were detected, a rate of $7.1 \%$ fetal trisomy among those women who had amnlocentesis for low MSAFP levels. No cases of trisomy 21 were missed. Thus far in 1986, over 10,000 women have been screened. The rate of fetal trisomy in amnsotic fluid is about $3 \%$. One infant with trisomy 21 is known to have been missed.

AN OPHTHALMOLOGICAL STUDY OF PATIENTS WITH WILLIAMS SYNDROME. Frank Greenberg, RIchard $\frac{\text { A. Lew1s, (Spon- }}{\text { sored by Arthur L. Beaudet), Baylor }}$

330 cine, Institute for Molecular Genetics, Department of Pediatrics Department of Ophthalmology, Houston, Texas.

Between July, 1982 and December 1986, 36 patients with Wil11 ams syndrome were evaluated. The mean age at examtnation was 8.2 years with a range of $0.5-43$ years. There were 30 whites, 2 blacks, 2 Hispanics, and 1 Aslan. There was a tendency toward ocular hypotelorism with short palpebral fissures; the mean inner canthal distance was $38 \%$ for age, while the outer canthal distance was $27 \%$. Of the white patients, 23 had blue irtdes, 6 hazel and 1 brown. All 6 non-white pateitns had brown irides. All patients with brown frides and, in addition, slx patients with blue and three patients with hazel irides did not have stellate tris patterns. Thirty-one percent of the patients had strabismus, stmflar to previous observations. Three types of optlc disc and vascular changes not previously descrtbed in the syndrome were noted. Hypermetroplc discs were noted ln 13 patients. Seventeen patients had simplex vertical branching and three had situs inversus vasorum. Although the latter two find ings are considered normal varlants, they seem more common in willams syndrome patients. Accentuated retinal vascular tortuosity has been previously reported, but was not present in any of our patients. In addition, no patients had evidence
ocular manffestations of hypercalcemia. Because of the high inctdence of ocular mantfestations in Williams syndrome, we recommend ophthalmologic evaluation of all such patients.

LISCH NODULES IN AN UNSELECTED POPULATION: PREVALENCE AND USEFULNESS AS INDICATION

331 Wendy s. Male, Shelley M.Coleman, Martin E. Ohrliok and Robert A. Gordon (Spon. by Emrliok and Robert A. Gordon (Spon. by Shapira). Tulane Univ Sch of Med. Human Genet Program and Dept of Ophth, New Orleans. Lisch nodules (LNS), which are found in the iris in neuropibromatosis (NF), were discovered in the otherwise unremarkable parents of two unrelated children with NF. While LNs have not been reported in the absence of NF, there are no studies which test the hypothesis that LNs are pathognomonio for NF. Need hypothesis that LNs are pathognomonic for NF. for accurate counseling of our famllies prompted a population. All pationts in two ophthalmology olinics were examined by slit lamp before dilation for the presenoe of LNs. Those with Iris trauma or surgery 600 patients have been screened and two ind1viduals discovered with one or more LNs. The first is a woman discovered with one or more LNs. The first is a woma with one small LN without evidence of NF by examina multiple cafe-au-la1ts and a selzure disorder, in whom a diagnosis of NF was considered following discovery of LNs and proven by blopsy of a skin tumor.

We suggest that LNs may be found in a limited number of individuals without NF. Nevertheless, we recommend examination for LNs in the ophthalmology clinic as a useful screening tool for NF. 